\title{
Ethical Issues In Palliative Care
}

\author{
${ }^{*}$ Ms.Manopriya\& $V^{* *}$ Dr.Renuka $K$
}

\begin{abstract}
:
Ethics refers to the rules or standards governing the conduct of individuals or members of a profession. The four cardinal principles of medical ethics provide a frame work foe decision making in difficult situation include Respect for patient's autonomy, Beneficence or 'do good, Non maleficence or 'do no harm', Justice or fare use of available resources., Practical application of ethics in palliative care.Interaction with patient and family with honest and clear information sharing is the key to ethical decision making.Ethical principles are useful only as a broad guideline for patient care. What is important is to apply it on an individual basis. Compassion and common sense should be combined with professional knowledge and skill. While applying ethical principles one should communicate well with the patient as well as the cares.
\end{abstract}

\section{Keywords: Ethical Issues and Decision Making}

\section{Introduction}

Ethics refers to the rules or standards governing the conduct of individuals or members of a profession. As members of medical profession our conduct is governed by medical ethics. When we have to redefine the goals of care towards the end of life, the ethical principles come into sharp focus. So it is mandatory that those involved in end of life care should have a thorough understanding about the ethical principles. ${ }^{1}$

The four cardinal principles of medical ethics provide a frame work foe decision making in difficult situation. They are-

1. Respect for patient's autonomy

2. Beneficence or 'do good'
3. Non maleficence or 'do no harm'

4. Justice or fare use of available resources.

Mr. $X$ is a 54 years old man with advanced cancer of stomach. He was a manual laborer and worked hard to support his wife and rear their four children. Now his children are all grown up and started to earn. When he became ill, he refused food and fluids. His wife and children upset at the thought that when the family reached a point when Mr. X can sit back and enjoy the fruit of his labor, he is unable to eat. They insist the doctor to put in an NG tube or to give him IV fluids. 
Autonomy is an expression of informed choices and preferences or consent to whatever we do or is done to as by others. It acknowledges the patient's right to know the diagnosis, to know the details of the treatment offered to him /her, and the right to refuse treatment.

Beneficence means that whatever one does to the patient should be for the good of the patient.

Non maleficence means one should not do any harm to the patient while caring for or treating the patient.

Justice is the principle of fare use of the available resources. The resources are limited and the demands or high. It concerns with balancing individual needs with those of society.

Now let us look at a clinical scenario-

\section{How do the ethical principles apply in the above clinical scenario?}

Respecting the autonomy means not to force feed him. Before taking such decision we have to be sure that his opinion came as an informed choice and not under any undue external pressure. To ascertain this we have to communicate with the patient effectively. ${ }^{3} \quad$ Psychological assessment must be done to rule out clinical depression, and anything correctable should be corrected. At times the patients tell us that they are not at all keen on taking any food or fluids because it increases their discomfort. If we know that Mr. X 's decision not to take food or fluids came as an informed choice we should respect it.

According to the principle of beneficence, artificial hydration or feeding should be given only if it does any good to the patient. Unfortunately very little research work has been done on the benefit of artificial hydration and nutrition in terminal patients. But all available studies uniformly point to the fact that terminal hydration and nutrition do not improve the QoL or longevity of terminal patient.

The principle of non- maleficence. We are justified in giving artificial hydration and nutrition only if it does not produce any harm to the patient. Any problem with artificial hydration in a terminally ill patient is circulatory overload and the resultant pulmonary edema. It also increases secretions and the need for frequent urination. This amounts to adding further distress to the patient. ${ }^{2}$

The principle of justice has not much relevance in this situation unless we plan for total parenteral nutrition which has a bearing on the resource potential. Thus applying the ethical framework of the cardinal principles of medical ethics, we can arrive at the right decision whether to give or not to give artificial feeding and hydration for this particular patient.

Now the question is to address the relative's concern. Again, skilled communication is needed. They should be informed in a sensitive manner the futility of hydration and nutrition in such patients and the possible adverse effects of such treatment. In our cultural setting it is not enough if we care about the autonomy of the patient taken in isolation. We live in a culture which upholds filial piety. Individual members of the family feel responsible for the sick person in their family. In this cultural milieu it is important that we respect the wishes of the immediate care giver also. This can be done by making the care givers participate in the decision making. ${ }^{5}$

\section{Practical application of ethics in palliative care:}

Informed consent: If we respect autonomy, it automatically follows that we should never do anything on the patient without the person's consent. 
- For ordinary, everyday procedures and medications, consent is implied; that is, the very fact that the person comes to us for treatment is taken to mean that the person is willing to receive medicines or be subjected to usual injections. But for any significant intervention, such as surgical procedure or the person being subjected to a medical research, written/ informed consent is essential. In the context of illiteracy, written consent of ten becomes meaningless. With the imbalance of power between the medical system and the person, he/she may sign any document without understanding it. It is our responsibility to ensure, whether literate or illiterate, that every person understands the implications of the procedures that we perform on them.

- Duty to alleviate suffering: Beneficence is too often considered only in the context of disease and cure. This in not right the physician has an obvious duty to alleviate suffering.

- Respect: every human being needs to be treated with respect and courtesy and their dignity should be preserved.

Confidentiality: we have the duty to preserve the persons confidentiality and do not have the rights to discuss matters related to his disease or psychological/social/spiritual issues with anyone other than the members of the treating team. In the context of todays' world of information- sharing and computerization, confidentiality can be easily breached. Respect for confidentiality requires our constant vigilance.
- Human Rights: it is important for health care personnel to understand current concepts of human rights- the right to be respected, the right for full disclosure of health information, the right to access to pain relief and the right to life and death with dignity.

- Ethics and the law: It is possible that what is ethically correct may be legally wrong. As citizens of a country, we need to respect the law despite our feelings of moral distress/ conflict about the ethics of a situation. ${ }^{4}$

\section{Euthanasia}

The Greek word 'euthanasia' simply means a gentle and easy death. But now the word is used to denote the act of international killing of the patient when the suffering of the patient could not be relieved and the death seems to be a benefit for the patient. There are several definition for euthanasia. One definition which is clear and unambiguous is that, "Euthanasia is a deliberate intervention undertaken with the express intention of ending life to relieve intractable suffering". According to this definition euthanasia is not simply a doctor doing something which he foresees will shorten the patient's life, but doing something intending to shorten patient's life. Stopping biologically futile treatments or stopping treatment when the burden and risk outweigh the benefit or using sedatives to relieve intractable mental suffering in a dying patient are not euthanasia. Some authors use the term 'passive euthanasia' to denote this condition. It is misnomer. Euthanasia can never be passive, as by definition it is a deliberate intervention undertaken with the express intention of ending life. In the formal situation they are only allowing nature to take its course or simply letting the patient die. Active debate is going on whether to legalize euthanasia or not. 
People who argue for euthanasia are of the opinion that there exists certain levels of existence where people wish not to be kept alive and they have a rights to ask for euthanasia as it is execution of once own autonomy. Those against euthanasia argue on several grounds - some believe it is morally wrong on the basis of theistic beliefs.

Some believe that is not appropriate at this point of the time when the $\mathrm{PC}$ coverage is too low as PC is a strong deterrent of euthanasia. There are also certain gray areas like the meaning is suffering, suffering as a possibility for personal growth etc. It will be difficulty to place euthanasia in a such scheme. At the same time there are compelling sentiments as Robert Twycross rightly puts :'a doctor who has never been tempted to kill a patient probably has had limited clinical experience or is not able to empathize with those who suffer. A doctor who leaves the patient to suffer intolerably is morally more reprehensible than the doctor who opts for euthanasia'. ${ }^{5}$

\section{Withholding and withdrawing futile treatment:}

With the advent of modern technology it is now possible to prolong the dying process by artificial ventilation and cardiac support. Most of the time it runs contrary to wishes of the patients and/ their relatives. It does not conform to the notion of 'good and dignified death, either. In what circumstance is it morally justified to stop life prolonging or life sustaining treatment? The decision has to be taken on an individual basis. The biological prospects of the patient should be taken into consideration. We have to take into consideration how the patient sees the situation and what his/her goals, ambitions, and wishes are.
With this background information, we can apply the ethical principles and arrive at a decision whether or not to stop life prolonging/ life sustaining treatment. In such situation death happens, not because of withholding or withdrawal of the treatment but as a result of the inevitable outcome of the terminal illness itself. Here ethical principle are applied against the background of respect for life and the acceptance of the ultimate inevitability of death. ${ }^{5}$

Indian law doesn't have any specific guideline for limiting life support in end of life care. In the absence such guidelines, the treating physician will be forced to continue all life prolonging measures which he knows is futile. The law commission of India in its 196 th report released in 2006 has suggested the need for a law amendment for stopping futile treatment.

The law commission in the 241th report released in 2012 much in line with the 196 th report presented a document for public discussion regarding the pros and cons of limiting futile treatment. The idea is to present a bill in the parliament on limiting futile treatment. Unfortunately both documents describe limiting futile treatment as passive euthanasia. ${ }^{5}$

In 2014 the Indian society of critical care medicine and the Indian association of palliative care have come up with a joint position statement on limiting futile treatment. They have prepared a guideline for limiting futile treatment in the Indian Critical Care units. 


\section{ETHICS-BASED DICISION MAKING}

Interaction with patient and family with honest and clear information sharing is the key to ethical decision making.
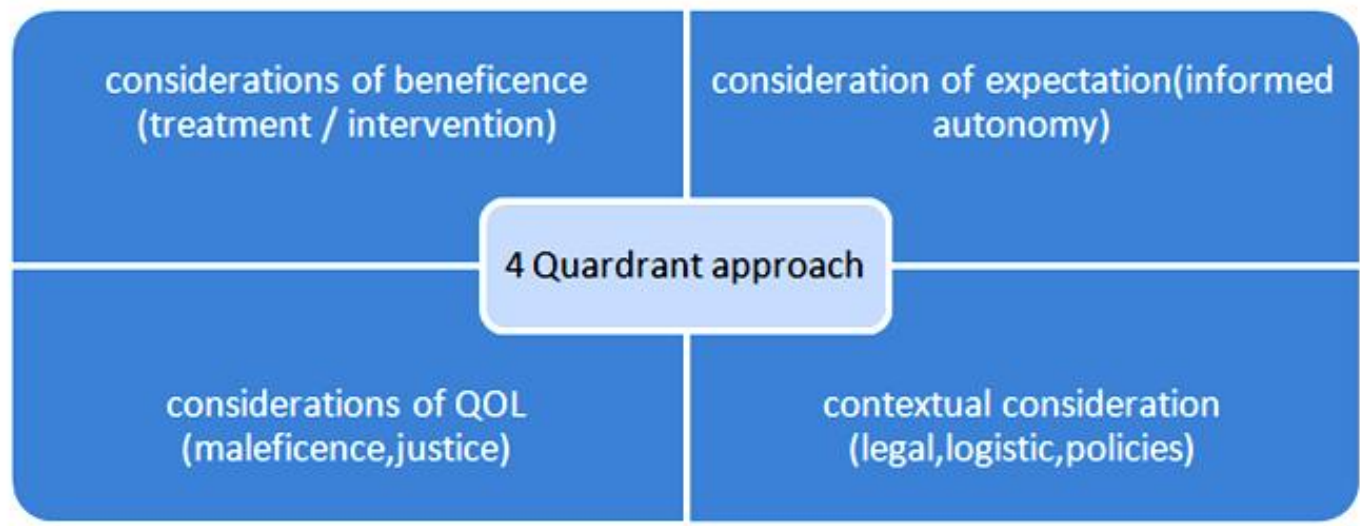

\section{Summary:}

Ethical principles are useful only as a broad guideline for patient care. What is important is to apply it on an individual basis. Compassion and common sense should be combined with professional knowledge and skill. While applying ethical principles one should communicate well with the patient as well as the cares. Essentially it is working together with the patient and family taking into consideration their social, religious and cultural background. 'Ideologies and systems of care that requires dichotomous thinking and blackand-white choices serve the patients and families very poorly.

\section{References:}

1. Randal F, Downie RS 1999. Palliative Care Ethics- A companion for all specialties. Oxford University press pp 8.
2. House of Lords (1994) Report of select committee on medical ethics. HL paper 21-1 HMSO, London.

3. Twycross RC (2003) introducing palliative care. institute of palliative medicine, medical college, Calicut-PP13)

4. David Barnard et al (2000) crossing over- narratives of palliative care Oxford University press. pp 11.

5. Morita T, et al 2006 Artificial Hydration Therapy, Laboratory Findings, and Fluid Balance in Terminally ill Patients with Abdominal Malignancies. Journal of pain and symptom Management pp 130-139. 